\title{
Brincadeira liure como promotora da habilidade comunicativa intencional de bebês
}

\author{
Juego libre como promotor de la habilidad comunicativa intencional de bebés \\ Free Play as a Promoter of the Intentional Communicative Ability of Infants
}

\author{
Ana Cristina Ramos Costa* \\ Fabíola de Sousa Braz Aquino \\ Universidade Federal da Paraíba
}

Doi: https://doi.org/10.12804/revistas.urosario.edu.co/apl/a.7054

\begin{abstract}
Resumo
$\overline{\text { Essa pesquisa investigou a habilidade de comunicação }}$ intencional infantil em contexto de brincadeira livre na interação mãe-bebê nos dois primeiros anos de vida. O objetivo principal foi analisar as modalidades de brincadeiras e o uso de gestos comunicativos intencionais de bebês durante situações de brincadeira livre. Participaram deste estudo seis díades mãe-bebê com idades de nove, doze e quinze meses. A análise dos episódios suscitou em três eixos gerais de análise: tipos de interações; tipos de brincadeiras realizadas entre as díades em cada período; e, atos comunicativos intencionais dos bebês durante o uso dos brinquedos e/ou objetos nas interações. Os resultados assinalaram variações nas habilidades de comunicação intencional dos bebês, nos tipos de uso de brinquedos e modalidades de brincadeiras nos três períodos interativos estudados, como também a importância do papel mediador do adulto no desenvolvimento de habilidades sociocognitivas e linguísticas. Ressalta-se
\end{abstract}

a contribuição desta pesquisa no sentido de produzir conhecimento que possa subsidiar programas de intervenção de profissionais que atuam em contextos de educação e de saúde com foco na promoção de desenvolvimento sociocognitivo e linguístico nos anos iniciais da vida do bebê.

Palavras-chave: interação mãe-bebê, intencionalidade comunicativa, brincadeira.

\section{Resumen}

Este estudio investigó la habilidad de comunicación intencional infantil en el contexto de juego libre en la interacción madre-bebé durante los dos primeros años de vida. El objetivo principal fue analizar las modalidades de juegos y el uso de gestos comunicativos intencionales de bebés durante situaciones de juego libre. Participaron de este estudio seis parejas madre-bebé con edades de nueve, doce y quince meses. El análisis de los episodios suscitó en tres ejes generales de análisis: tipos de interacciones; tipos de

* Dirigir correspondencia a Ana Cristina Ramos Costa, Universidade Federal da Paraíba, João Pessoa, PB. Correio eletrônico: anacristinaramoscosta@gmail.com

Para citar este artigo: Costa, A. C. R., \& Braz Aquino, F. de S. (2019). Brincadeira livre como promotora da habilidade comunicativa intencional de bebês. Avances en Psicología Latinoamericana, 18-32. https://doi.org/10.12804/revistas.urosario.edu.co/ ap1/a.7054 
juegos realizados entre las díadas en cada periodo; y actos comunicativos intencionales de los bebés durante el uso de los juguetes y objetos en las interacciones. Los resultados indican variaciones en las habilidades de comunicación intencional de los bebés, en los tipos de uso de juguetes y en las modalidades de juegos en los tres periodos interactivos estudiados, como también en importancia del papel mediador del adulto en el desarrollo de habilidades sociocognitivas y lingüísticas. Se resalta la contribución de esta investigación en el sentido de producir conocimiento que pueda subsidiar programas de intervención de profesionales que actúan en contextos de educación y de salud con énfasis en la promoción del desarrollo sociocognitivo y lingüístico en los años iniciales.

Palabras clave: interacción madre-bebé, intencionalidad comunicativa, juego.

\section{fibstract}

This research investigated the ability of intentional child communication in the context of free play in mother-infant interaction in the first two years of life. The main objective was to analyze the play patterns and the use of intentional communicative gestures of babies during situations of free play. Six mother-infant dyads with ages of nine, twelve, and fifteen months participated in this study. The analysis of the episodes rose in three general axes of analysis: types of interactions, types of games played between the dyads in each period and intentional communicative acts of the babies during the use of the toys or objects in the interactions. The results point to variations in the intentional communication skills of infants, types of use of toys and play patterns in the three interactive periods studied, as well as the importance of the mediating role of adults in the development of socio-cognitive and linguistic abilities. The research produces knowledge that can subsidize intervention programs of professionals that work in educational and health contexts with a focus on the promotion of socio-cognitive and linguistic development in the initial years.

Keywords: Mother-baby interaction, communicative intentionality, play.
Estudiosos do desenvolvimento humano inicial (Esteve-Gilbert, \& Prieto, 2013; Hamann, Warneken, \& Tomasello, 2012; Heesen, Genty, Rossano, Zuberbühler, \& Bangerter, 2017; Legrain, Destrebecqz, \& Gevers, 2012; Legerstee, 2013; Schulze, \& Tomasello, 2015) têm investigado a capacidade humana de compartilhamento da atenção e intenções com seus pares, explorando as habilidades de bebês humanos, desde o primeiro ano de vida, para compreender e interpretar as intenções daqueles com os quais estabelecem intercâmbios sociais.

As primeiras interações estabelecidas entre adultos e bebês são consideradas essenciais para a construção de habilidades sociocomunicativas intencionais, uma vez que os bebês são motivados desde muito cedo a compartilhar o interesse e a atenção com outros (Rossano, Carpenter, \& Tomasello, 2012; Schulze, \& Tomasello, 2015; Tomasello, \& Carpenter, 2007). A habilidade de comunicação intencional pode ser compreendida como a coordenação, por parte dos bebês, das ações dirigidas a um objeto ou a outra pessoa, demandando da criança a comunicação de intenções para outros indivíduos que podem ajudá-los a satisfazer seus objetivos (Behne, Liszkowski, Carpenter, \& Tomasello, 2012; Rivero, 2003; Sarriá, 1991; Striano, \& Vaish, 2006).

Para que a criança desenvolva esse tipo de habilidade é fundamental a interação social mediada, uma vez que, por meio dela a criança cria formas características de aprendizagem cultural (Nunes, \& Aquino, 2014; Tomasello, 1999; 2003; Tomasello, \& Carpenter, 2007). Tal habilidade é considerada um dos pilares da cognição social infantil e do desenvolvimento da fala, constituída a partir das primeiras trocas intersubjetivas dos bebês com outros sujeitos, em um contexto cultural (Carpenter, Nagell, \& Tomasello, 1998; Hamann et al., 2012; Tomasello, 1995).

Autores como Tomasello (2003) assinalam que reconhecer o outro enquanto coespecífico é um processo essencial para o desenvolvimento 
da comunicação intencional. Assim, o elemento fundamental de explicação para a intencionalidade comunicativa encontra-se justamente nas primeiras interações sociais, pois é devido à interação adulto-bebê que este último desenvolve a comunicação intencional. Isto porque, ao interagir com os bebês, geralmente as mães costumam atribuir significados e intenções aos movimentos, gestos e sons produzidos por eles que, de forma recíproca, aprendem pela regulação conjunta (Aquino, \& Salomão, 2011; Delafield-Butt, \& Trevarthen, 2015; Mendes, \& Seidl de Moura, 2009; Nogueira, \& Seidl de Moura, 2007).

As primeiras intenções comunicativas são expressas apenas em torno dos oito a dez meses (Melinger, \& Levelt, 2004; Rivero, 2003; Striano, \& Rochat, 1999; Tomasello, \& Carpenter, 2007) quando, por meio de gestos, alternância de olhares e vocalizações, o bebê passa a compreender que o outro tem metas e se comporta de forma a atingi-las. Para Tomasello (2003), a habilidade de comunicação intencional tem início por volta dos nove meses de idade, quando o bebê começa a apresentar um conjunto de comportamentos estabelecidos por meio das relações triádicas (adulto-bebê-objeto). Tais comportamentos podem ser exemplificados por atos como: alternância do olhar entre a mãe, um objeto e novamente a mãe (dirigindo a atenção por meio do olhar); pegar objetos e oferecer; apontar para algo ou alguém; iniciar uma interação como bater palmas e sorrir olhando para a mãe; vocalizar e olhar para a mãe, dentre outros. Assim, de forma recíproca, o adulto, ao interpretar e atribuir significados às ações da criança colabora para que ela desenvolva formas de comunicação intencional.

Em estudos recentes, Aureli et al. (2017) e Esteve-Gilbert e Prieto (2013) defenderam que os bebês, ao se aproximarem dos doze meses de vida, começam a usar suas habilidades motoras para fins sociais, produzindo gestos representativos e dêiticos que visam comunicar intenções e significados. Com o desenvolvimento, as configurações gestuais dos bebês vão se integrando às modalidades vocais e os gestos motores acompanham a aquisição da fala sendo parte integrante da comunicação. Foi observado também por Novack e Goldin-Meadow (2017) que bebês com doze meses de idade possuem a capacidade de distinguir entre os diferentes tipos de intenção sociocomunicativa interpretando as características da fala e formas gestuais que acompanham o comportamento do adulto. Outras pesquisas com bebês de doze, quinze e dezoito meses de idade apontam que eles são capazes de expressar intenções comunicativas por modalidades vocais e gestuais (Behne, Carpenter, \& Tomasello, 2005; Behne et al., 2012).

Esteve-Gilbert e Pietro (2013) ao realizarem um estudo longitudinal com bebês de sete, nove e onze meses destacaram em seus resultados que, as crianças entre os nove e onze meses aumentaram significativamente o número total de vocalizações comunicativas e à medida que suas habilidades de comunicação se desenvolveram, elas produziram intencionalmente uma ampla variedade de comportamentos que incluíram desde expressões de satisfação e descontentamento, pedidos, respostas e declarações, além de vocalizações que expressavam surpresa.

O presente trabalho irá destacar um tipo de interação específica que pode favorecer o desenvolvimento de habilidades sociocomunicativas intencionais, quais sejam, aquelas que ocorrem em contexto de brincadeira livre. Considerada um dos principais elementos da vida da criança, a brincadeira tem como base as relações sociais que se estabelecem em um contexto histórico-cultural (Elkonin, 2009; Leontiev, 1988). A importância da brincadeira vem sendo ratificada por autores que defendem tal atividade como uma ação social contextualizada, uma experiência concreta e central na vida da criança, que auxilia no desenvolvimento da cognição, da afetividade, da motricidade e da dimensão sociocomunicativa (Oliveira, Braz-Aquino, \& Salomão, 2016, Smirnova, \& Riabkova, 2016). 
Heesen et al. (2017) discutiram em sua pesquisa as ocorrências de atividades conjuntas em contextos de brincadeira. Para eles, a brincadeira é uma forma de ação conjunta que parece necessitar de um tipo particular de ajustes entre os parceiros de uma interação e se constitui em um contexto privilegiado para estudar a evolução da intencionalidade compartilhada, própria dos seres humanos. As reflexões de Heesen et al. (2017) em torno do papel da ação conjunta em contexto de brincadeira para o desenvolvimento da comunicação intencional reforçam a ideia de que a brincadeira constitui-se em uma experiência cultural e histórica mediada (Vigotski, 1986; 2008), um processo complexo que amplia os conhecimentos da criança sobre o mundo e sobre si, de forma prospectiva.

Considerando que as pesquisas relativas ao tema da intencionalidade comunicativa afirmam que os bebês humanos desde muito cedo são motivados a compartilhar o interesse e a atenção com outros (Tomasello, \& Carpenter, 2007) defende-se, amparadas nas pesquisas acima referidas, a situação da brincadeira livre como promotora de habilidades comunicativas intencionais infantis. Nas interações estabelecidas durante a brincadeira livre a mãe, ao estabelecer o contato visual com o bebê, perceber e estar atenta às expressões e atos dele, pode favorecer o estabelecimento de ações conjuntas que colabora para manter a interação entre ambos (Amorim, Costa, Rodrigues, Moura, \& Rosseti-Ferreira, 2012; Seidl de Moura, \& Ribas, 2000).

Diante do exposto, o objetivo da presente pesquisa é analisar as modalidades de brincadeiras e o uso de gestos comunicativos intencionais de bebês aos nove, doze e quinze meses, em situação de brincadeira livre com as mães.

\section{Método}

Trata-se de um estudo observacional de delineamento transversal.

\section{Participantes}

Seis díades mãe-bebê distribuídas igualmente nas idades de nove, doze e quinze meses. A idade das mães variou entre 25 e 36 anos, com média de 30 anos ( $\mathrm{DP}=3,49)$. No que se refere ao nível instrucional das mães duas delas tinham o ensino médio completo, três mães tinham concluído o ensino superior, e uma pós-graduação. Todas as mães eram casadas e residiam em seus domicílios. Todos os bebês nasceram a termo e não foram referidos pelas mães problemas no desenvolvimento dos bebês. Referente ao sexo dois bebês eram meninos e quatro meninas.

Tabela 1.

Quadro referente aos dados sociodemográficos das díades participantes do estudo

\begin{tabular}{ccclc}
\hline Díade & $\begin{array}{c}\text { Sexo dos } \\
\text { bebês }\end{array}$ & $\begin{array}{c}\text { Idade dos } \\
\text { bebês }\end{array}$ & $\begin{array}{c}\text { Nível } \\
\text { instrucional } \\
\text { das mães }\end{array}$ & $\begin{array}{c}\text { Idades das } \\
\text { mães }\end{array}$ \\
\hline Díade 01 & Feminino & 9 meses & $\begin{array}{l}\text { Médio } \\
\text { Completo }\end{array}$ & 28 \\
\hline Díade 02 & Feminino & 9 meses & $\begin{array}{l}\text { Superior } \\
\text { Completo }\end{array}$ & 32 \\
\hline Díade 03 & Masculino & 12 meses & $\begin{array}{l}\text { Médio } \\
\text { Completo }\end{array}$ & 25 \\
\hline Díade 04 & Feminino & 12 meses & $\begin{array}{l}\text { Pós-Gra- } \\
\text { duação }\end{array}$ & 29 \\
\hline Díade 05 & Masculino & 15 meses & $\begin{array}{l}\text { Superior } \\
\text { Completo }\end{array}$ & 32 \\
\hline Díade 06 & Feminino & 15 meses & $\begin{array}{l}\text { Superior } \\
\text { Completo }\end{array}$ & 36 \\
\hline
\end{tabular}

\section{Instrumentos}

Foi utilizado a observação, um questionário sociodemográfico e uma entrevista semiestruturada para levantar informações sobre as mães e os bebês. Como material observacional utilizou-se uma câmera de vídeo, lápis e papel para possíveis anotações. Destaca-se que as observações foram realizadas nas casas das mães dos bebês, visando apreender os aspectos da interação de forma o mais espontânea possível por estarem em seu ambiente natural e, portanto, mais conhecido para as díades. 


\section{Procedimento para coleta e análise das observações}

Inicialmente procedeu-se com a submissão da pesquisa ao Comitê de Ética do Centro de Ciências da Saúde da Universidade Federal da Paraíba (UFPB), seguindo os procedimentos éticos para pesquisa com seres humanos da Resolução 466/2012 do Conselho Nacional de Saúde. Os participantes foram definidos de forma aleatória, sendo indicado por pessoas que conheciam a pesquisadora e pelos próprios participantes. O contato inicial com as mães foi realizado por telefone quando foram explicitados os objetivos da pesquisa. Ao concordar com a participação no estudo era marcada uma primeira visita na casa das mães, quando a pesquisadora retomava os objetivos da pesquisa, esclarecendo possíveis dúvidas apresentadas. Logo após reafirmado o interesse das mães de participar da pesquisa, foi assinado pelas mães o Termo de Consentimento Livre e Esclarecido (TCLE).

A única instrução dada às mães era que elas "brincassem com o bebê da forma como faziam usualmente". Os registros das interações das díades tiveram a duração de 30 minutos, sendo retirados da análise os 10 primeiros e os 10 últimos minutos de cada videogravação, procedimento que permitiu apreender a dinâmica das interações e identificar os tipos de brincadeiras e usos de comunicação intencional de bebês durante o uso dos brinquedos. Os fluxos interativos mãe-bebê foram transcritos literalmente, segundo a segundo, possibilitando uma transcrição minuciosa dos episódios da interação e das atividades realizadas no contexto de brincadeira por cada díade (Aquino \& Salomão, 2011).

Após a transcrição das interações iniciou-se o processo de análise dos episódios. Essa análise foi realizada a partir da organização do material em três eixos gerais de análise: tipos de interações (diádicas, triádicas ou colaborativas); tipos de brincadeiras realizadas entre as díades em cada período; e, atos comunicativos intencionais dos bebês durante o uso dos brinquedos e/ou objetos nas interações. Esses eixos foram extraídos considerando os objetivos da pesquisa e as transcrições das interações. Para a análise dos comportamentos intencionais e dos episódios de brincadeira, tomouse como base a pesquisa de Aquino e Salomão (2011), e o estudo de Oliveira et al. (2016), respectivamente. Partindo desse último estudo e considerando o período do desenvolvimento dos bebês que participaram da presente pesquisa, duas categorias do brincar foram analisadas, quais sejam: o brincar exploratório e o brincar convencional. $\mathrm{O}$ brincar exploratório foi definido como uma atividade de explorar/manipular o brinquedo como, por exemplo, ao observar e manusear um objeto. Já o brincar convencional é caracterizado pelo uso formal e cultural do brinquedo, tais como: chutar uma bola, tocar as teclas de um piano de brinquedo e encaixar peças em um quebra-cabeça.

A delimitação do início e término de cada episódio teve como referência o estudo de Aquino e Salomão (2011) o qual demarcou a quebra dos episódios pela mudança de tópico do diálogo, da mudança de brinquedos manuseados pelas díades, brincadeiras ou troca de objetos nos quais estavam engajadas as díades. Foram considerados comportamentos comunicativos intencionais dos bebês, ações que demonstravam sua habilidade em se comunicar com a mãe ou em utilizar objetos intencionalmente, como por exemplo: olhar fixamente para a mãe; procurar a mãe no ambiente; dirigir a atenção por meio do olhar; mostrar objetos; dar objetos espontaneamente; apontar, vocalizar, dentre outros (Papaeliou \& Trevarthen, 2006; Sarriá, 1991).

\section{Resultados e discussão}

Nessa seção descrevem-se as análises das interações realizadas com as mães dos bebês aos nove, doze e quinze meses, as quais ocorreram pela escolha da maioria das mães na sala de estar, variando em cada díade no que se refere à disposição dos móveis e sua quantidade. Uma das mães 
comunicou que brincava mais com a criança no quarto, local onde foi realizada a observação com essa díade. Verificou-se, por meio da análise das interações, que houve variações no uso dos brinquedos bem como na participação dos membros das díades em cada grupo de idade, como será observado a seguir.

\section{Díades mães-bebês aos nove meses}

A análise das interações das mães com os bebês de nove meses permitiu identificar cinco episódios de brincadeira conjunta e seus respectivos tempos durante as interações. Destes episódios um foi considerado do tipo exploratório (episódio 1: "a caixa de madeira" 0:06'); dois do tipo convencional (episódio 3: "se escondendo" 1:28'; episódio 4: “a bolinha de papel" 1:16'); e dois do tipo exploratório e convencional (episódio 2: "a garrafa pet" 3:17'; e episódio 5: “a boneca” 0:40').

Em relação aos brinquedos usados nos episódios interativos percebeu-se que houve transformações de objetos em brinquedos, como a garrafa pet que foi utilizada como objeto musical, e a folha de papel que foi transformada em bola de papel. Também foram observados objetos como uma caixa de madeira e uma fralda de pano, e como brinquedo uma boneca de plástico. Referente aos atos comunicativos intencionais utilizados pelos bebês em tais contextos foram identificados: observar fixamente objeto manuseado pela mãe, olhar alternado entre a mãe e o objeto, e pegar objeto da mão da mãe. Tais comportamentos também foram observados em estudos realizados por Mendes e Seidl-de-Moura (2004), Mendes e Seidl-de-Moura (2009) e Oliveira et al. (2016), os quais perceberam brincadeiras de bebês no primeiro ano de vida envolvendo toques, vocalizações e expressões faciais.

Do conjunto de observações realizadas, serão destacados os episódios que mais ilustraram os tipos de brincadeira e de comportamentos intencionais em cada período de idade. Desta forma, no episódio 2 realizado pela díade 1 ("a garrafa pet") foi observado o manejo com uma garrafa plástica transformada pela mãe e utilizada como brinquedo musical (mãe colocou grãos de feijão dentro dela) para a filha. Nesse episódio foram identificados atos conjuntos triádicos que tiveram início quando a mãe solicita a atenção da bebê e aponta para que ela pegue a garrafa que estava um pouco distante dela e ela não conseguia pegar. A bebê não atende a solicitação da mãe e observa os movimentos que ela realiza para pegar a garrafa. Ao pegar a garrafa a mãe olha para a bebê e começa a balançá-la. A garrafa emite barulho, e a mãe fala: "dança! canta a música". Em um outro momento da mesma brincadeira, "a mãe solta a garrafa no chão e bate palmas olhando para a bebê. A bebê olha para a mãe, pega a garrafa no chão, olha novamente para a mãe, dá gritinhos olhando para ela, sorri e balança a garrafa". Percebe-se neste recorte que a mãe faz uso do recurso musical para interagir e manter a atenção da criança, pois por meio da música, concomitante ao manuseio do brinquedo, a mãe busca estabelecer contato com a filha.

Nesse episódio evidencia-se a função mediadora da brincadeira que se interpôs entre a mãe e as respostas que o bebê emite por meio de atos intencionais. Esse recorte permite ressaltar a importância que a brincadeira tem para o desenvolvimento sociocognitivo e linguístico da criança, pois por meio dela a criança respondeu às solicitações da mãe e se manteve na interação. É possível frisar ainda sobre este contexto a relação proposta por Escandón (2008) entre musicalidade e brincadeira desde o início de vida dos sujeitos, que favorece a comunicação de emoções e situações que estão além das palavras. A utilização da música em episódios de brincadeira tem um papel importante no desenvolvimento cognitivo e emocional, pois potencializa funções psicológicas superiores como a imaginação, linguagem, atenção e memória, como também contribuir de forma eficaz no processo de aprendizado. 
Recortes como estes demonstram a responsividade da mãe que, ao estabelecer o contato visual, observa as expressões e atos da bebê mantendo-se atenta à interação. Nesse ponto retoma-se a ideia de que a sensibilidade e responsividade maternas aos comportamentos do bebê tem a função de intermediar as relações dele com o mundo (Amorim et al., 2012; Seidl de Moura \& Ribas, 2000).

Em outro recorte deste mesmo episódio, a interação transcorre da seguinte forma:

... a bebê olha para o objeto que a mãe manuseia e permanece atenta olhando a mãe balançar a garrafa. A bebê que estava sentada de frente para a mãe olhando para a garrafa ergueu seu corpo um pouco para frente e estendeu seu braço com a mão aberta para pegar a garrafa que a mãe segurava. A mãe então soltou a garrafa no chão e bateu palmas olhando para a bebê. A bebê olhou para a mãe, pegou a garrafa no chão, olhou novamente para a mãe, deu gritinhos olhando para ela, sorrindo e balança a garrafa. A mãe, olhando para a bebê, sorri e bate palmas.

Sobre esse trecho da interação, estudiosos (Liszkowski, 2005; Messinger \& Fogel, 1998; Novack \& Goldin-Meadow, 2017) referem que os bebês na faixa etária dos nove meses exibem gestos como: apontar, acenar, erguer a mão aberta para pegar algo, pegar algo e oferecer, considerados como intencionais por indicarem a intenção de comunicar algo para o outro. Sobre essa questão, Papaeliou e Trevarthen (2006) afirmaram que, já a partir dos quatro meses de vida são evidenciadas respostas diferenciadas quando os bebês interagem com um objeto e um parceiro, indicando que a habilidade do bebê em compreender as intenções comunicativas dos adultos pode ser observada no primeiro semestre de vida. Para esses autores, os atos de olhar para a mãe e pegar objetos oferecidos por ela são exemplos desta habilidade. Apoiando estes argumentos, Aureli et al. (2017) citam que no final do primeiro ano de vida, os bebês começam a usar suas habilidades motoras para fins sociais, produzindo gestos representativos e dêiticos que visam comunicar intenções e significados.

Para além destas considerações, observa-se que o trecho interativo retrata um tipo de brincadeira convencional devido ao uso esperado que o bebê faz do brinquedo, ou seja, embora a garrafa plástica tenha inicialmente outra função, por meio da transformação que a mãe realiza com o objeto ela se torna um brinquedo musical em que o bebê demonstra entender sua função. Isto porque todas as vezes que a bebê pegou a garrafa ela a balançou, o que pode indicar que, pela observação do comportamento da mãe durante a interação, a bebê imita os movimentos da mãe com este objeto específico.

No recorte interativo observado pela díade 2, episódio 4 ("bolinha de papel"), a brincadeira teve início no momento em que a mãe pegou uma folha de papel, amassou-a e a transformou em uma bola pequena, como descrito no seguinte trecho:

A mãe, observando os movimentos da bebê, pega da mão da bebê o papel que ela esfregava no chão e começa a amassar; logo em seguida ela olha para a bebê e estende o braço com a bolinha na mão oferecendo a bolinha à bebê. A bebê olha para a mãe, mas, não pega a bola. Em seguimento, a mãe pega a bolinha e ergue sua mão para cima e joga a bolinha do alto no chão dizendo:"ihhhhhh!!!”; a bebê acompanha atentamente os movimentos da mãe com a bola. Novamente a mãe ergue a mão para cima, olha para a bebê que olha para ela, sorri e joga a bola no chão dizendo: "lá vem, lá vem, a bolinha de novo, vai cair, vai cair, pufttt". A bebê sorri enquanto acompanha com os olhos os movimentos da bolinha que a mãe suspende e joga no chão.

Este trecho de interação aponta atos conjuntos triádicos que envolvem a criança, o adulto e alguma entidade externa para a qual ambos dirigem seus esforços (Viana \& Pedrosa, 2014), também designados por Tomasello et al. (2005) como 
engajamentos conjuntos, fundamentais para a cognição social infantil (Aquino \& Salomão, 2010). Nesse caso, a folha de papel, ao se tornar um brinquedo, passou a cumprir a função no brincar (Flores \& Maggi, 2012) quando a mãe utilizou a estratégia de transformar o papel em bolinha para iniciar e manter a brincadeira com a filha.

Em outro recorte da interação desse mesmo episódio observa-se a seguinte cena:

A mãe joga a bola mais uma vez e esta cai entre as pernas da bebê; a bebê, então, pega a bola, a observa, manuseia, aperta, estende seu braço para frente e joga a bola no chão imitando o movimento que a mãe realizara anteriormente. A mãe então pega a bolinha do chão, olha para a bebê e diz: "assim oh!!" e joga a bola no chão emitindo sons quando a bola caía no chão: “ihhhhh!! Pufftt”. A bebê, olhando para a mãe, sorri e tenta pegar a bola da mão da mãe, mas a mãe não solta a bolinha e a bebê então fica só observando a mãe jogar a bola.

Identificam-se nessa cena os atos comunicativos intencionais de estender os braços em direção à bolinha para pegá-la, e imitar o comportamento da mãe de jogar a bolinha. A respeito do comportamento de imitação, pesquisadores (Carpenter, Tomasello, \& Striano, 2005; Tomasello, \& Carpenter, 2007; Tomasello \& Rakoczy, 2003) relataram que bebês com um ano de idade frequentemente respondem à instrução do outro, imitam com motivação para compartilhar e comunicar algo para o outro e para demonstrar ao adulto que eles estão "em sintonia" com a situação atual. Durante as interações com o adulto os bebês observam suas ações direcionadas a eles e, em seguida, revertem os papéis e redirecionam as ações para o adulto, olhando fixamente para o rosto dele, o que favorece a ocorrência de ações e atenção conjunta. Além disso, o ato de imitar requer da criança estruturas cognitivas mais complexas, pois pressupõe uma compreensão da intenção subjacente à ação comunicativa do adulto (Behne et al., 2012).
No recorte interativo da bolinha de papel também é possível evidenciar dois tipos de brincadeira, qual seja, a exploratória, quando a bebê pega a bola e a manuseia, e posteriormente de forma convencional, quando a mãe transforma o papel em bola e ambas brincam com o objeto. Desta forma, a bebê parece ler a intenção comunicativa da mãe e imita seus atos, executando a brincadeira como proposto por ela. A respeito do brincar exploratório, Marques e Bichara (2011) afirmam que a exploração parece preceder a brincadeira, ou seja, crianças de todas as idades exploram um objeto ou buscam conhecer suas propriedades antes mesmo de brincar com ele.

\section{Díades mães-bebês aos doze meses}

No grupo de bebês de doze meses foi possível observar cinco episódios de brincadeira conjunta e o tempo de cada episódio nas interações. Destes episódios quatro foram considerados do tipo convencional (episódio 1: "a raquete", com 1:10'; episódio 2: "o carrinho de fricção", $\operatorname{com} 2: 06$ '; episódio 3: "encaixe de peças na girafa", com 2:43'; e episódio 4: "montar a árvore”, com 0:47'. Apenas um episódio foi identificado como exploratório (episódio 5: “o pião 0:40”).

Em relação aos brinquedos dispostos durante a interação menciona-se: um par de raquetes de plástico, um carrinho pequeno de fricção, várias peças pequenas de encaixe, uma girafa vasada para encaixe de peças, um quebra-cabeça de peças grandes.

Os atos intencionais utilizados nesses episódios consistiram em: realizar o encaixe correto de peças geométricas em uma girafa que tinha uma abertura na boca para inserção dessas peças, seguido da solicitação materna para tal, e imitar o comportamento da mãe de colocar o carrinho de fricção para andar após solicitação da mãe. Esse resultado foi anteriormente encontrado em estudos (Haman et al., 2012; Rossano et al., 2012; Tomasello, 1995; 2003) que identificaram evidências em bebês de um ano de idade que começam a demonstrar comportamentos colaborativos em interações nas quais 
ocorre imitação, tais como: observar as ações dos adultos direcionadas a eles, e em seguida, reverter os papéis e redirecionar as ações de volta ao outro, episódios que podem configurar ações conjuntas e trocas intersubjetivas mais complexas.

Para a análise dos resultados foram descritos os episódios que mais ilustram comportamentos intencionais e variações nas brincadeiras. $\mathrm{O}$ episódio 3 ("encaixe de peças na girafa") observado pela díade 1, evidencia atos conjuntos de forma colaborativa e intencionais que envolvem comportamentos meio-fim, exemplificados pela ação do bebê com o objeto oferecido pela mãe, quando ela pega um cubinho e oferece à bebê, e esta última sorridente olha para a peça na mão da mãe. O episódio tem início quando a bebê, sentada no colo da mãe e de costas para ela, se deita no colo da mãe e puxa o brinquedo para perto dela, como ilustrado no trecho a seguir:

A mãe ajudou a bebê a se sentar e colocou a girafinha no chão na frente de ambas. A bebê sorriu olhando para o brinquedo e colocou um braço dentro da boca da girafinha. Neste momento a mãe pegou em sua lateral um cubinho de encaixar na girafa e ofereceu à bebê. A bebê, sorrindo, olhou para a peça na mão da mãe, pegou-a e colocou diretamente dentro da boca da girafinha. A mãe observando a bebê diz: "eitaa, colocou a peçinha foi?". A bebê sem olhar para a mãe põe a mão dentro da girafinha e retira a peça que tinha colocado. A mãe pega outra peça no chão e oferece à bebê. Ela sem olhar para a mãe pega a pecinha e vai encaixar no brinquedo.

Ilustram-se neste trecho interativo as respostas não verbais do bebê dirigidas à mãe ao pegar as peças oferecidas por ela, sorrindo, mas sem olhar para a mãe, evidenciando a participação da bebê na brincadeira. Este recorte interativo evidencia também que a bebê interage com o brinquedo de forma convencional pelo uso e manuseio adequados do objeto. Este comportamento pode ser percebido geralmente quando há um contato prévio da criança com o objeto que foi apresentado pelo membro mais experiente na interação, no caso aqui citado, a mãe. Sobre a participação do adulto nas interações com crianças, Elkonin (2009) afirma que, para a criança aprender a forma convencional de uso do brinquedo, a mediação do adulto é essencial, pois é ele quem irá demonstrar para a criança os modos de execução do objeto permitindo que a criança gradativamente realize-o com autonomia.

Em outra observação, díade 2, episódio 2 (“o carrinho de fricção”), o bebê dá início a interação quando pega um cubinho de plástico no chão e o coloca no colo da mãe, como descrito a seguir:

A mãe pegou um carrinho que estava em sua lateral, colocou no chão, pegou a peça que o bebê tinha colocado em seu colo e encaixou em cima do carrinho. O bebê acompanhou com o olhar os movimentos que a mãe fez com o brinquedo. A mãe afastou alguns brinquedos e friccionou o carrinho no chão que se movimentou para frente. O bebê fez uma expressão de surpresa e estendeu o braço para pegar o carro. Ao pegar o carro ele tentou reproduzir o movimento que a mãe acabara de fazer; não conseguindo, ele retirou a peca que estava encaixada no carro, põe no chão e olha para a mãe. A mãe olhando para o bebê fala:"o que foi?"; o bebê então olhou para ela, olhou para o chão, pegou um objeto colocou na boca, olhou novamente para a mãe e olhou em direção à pesquisadora.

Neste trecho destaca-se a interação triádica, bem como a ação espontânea do bebê em iniciar a interação ao pegar o objeto e colocar no colo da mãe, de forma recíproca, a mãe responde ao propor a brincadeira. Essa resposta da mãe ao comportamento do bebê favorece a construção de significados e o desenvolvimento sociocognitivo deste, dado que pela sua ação, oportuniza as relações do bebê com o mundo que o cerca (Amorim et al., 2012; Seidl de Moura, \& Ribas, 2000). 
No que se refere aos atos intencionais do bebê observados durante a brincadeira, destacam-se: acompanhar com o olhar os movimentos que a mãe realiza com o carrinho; imitar movimentos realizados pela mãe com o carrinho, demonstrando um uso intencional do brinquedo; e oferecer o brinquedo para a mãe. Tais atos corroboram os dados do estudo de Hessen et al. (2017) ao destacar que os contextos de brincadeira são promotores das habilidades sociocomunicativas, uma vez que os potenciais marcadores comportamentais de intencionalidade compartilhada neste contexto são o estabelecimento de atenção conjunta, a coordenação e inversão de papéis, as trocas de turno, e o apoio mútuo.

Concernente ao tipo de brincadeira neste episódio é observado o brincar convencional demonstrado pelo tipo de uso que o bebê faz do carrinho, por exemplo, ao tentar reproduzir os movimentos que a mãe havia realizado, dando indícios de que compreende a função do carrinho, ao imitar a ação da mãe. A imitação observada no comportamento do bebê é citada por estudiosos (Carpenter et al., 2005; Viana \& Pedrosa, 2014) como tendo a finalidade de indicar à mãe a intenção de brincar com ela e que eles estão "em sintonia" com a situação.

\section{Díades mães-bebês aos quinze meses}

Nas duas díades mãe-bebê deste grupo etário foi possível observar seis episódios de brincadeira conjunta todas identificadas como convencionais. Episódio 1: “o dinossauro" 2:30'; episódio 2: "o Mickey” 1:05’; episódio 3: “o leão” 0:40’; episódio 4: "peças de encaixe" 1:30; episódio 5: "o livro" 2:00'; e episódio 6: "chaves de plástico" 0:43. Os brinquedos utilizados pelos bebês nas interações consistiram em um dinossauro de plástico que emitia som, um boneco do personagem Mickey, um leão de pelúcia, peças de encaixe de blocos, um livro de histórias e um molho de chaves coloridas de plástico.

Os principais comportamentos intencionais observados foram os gestos de apontar, bem como o uso de verbalizações. Assim como nas outras díades destacamos os episódios mais representativos para evidenciar o uso da comunicação intencional de bebês durante as interações com os brinquedos. Identifica-se na díade 2, episódio 1 ("o dinossauro"), brinquedo usado por uma das díades durante a interação. O episódio tem início da forma como se segue:

... o bebê caminha até uma grande caixa de brinquedos e pega dentro da caixa um dinossauro de brinquedo. A mãe, por sua vez, aproxima-se do bebê olhando para ele, faz expressão de surpresa e com a voz em falsete diz: "eeeeitahhh, o dinossauro!!!!" como é que o dinossauro faz?". O bebê olhando para o brinquedo aperta um botão que tem no dinossauro e o brinquedo emite som de dinossauro. A mãe olhando para o bebê e sorrindo faz "uarrruuu" e aperta a bochecha do bebê perguntando: “como é que o dinossauro faz?". O bebê novamente aperta o botão olhando para o brinquedo. A mãe olhando para o bebê com expressões bem demarcadas pergunta: "como é que o dinossauro faz? diz aí pra mamãe? como é?" e fala "uaarrrrr". O bebê que está manuseando o dinossauro novamente aperta o botão, que emite som e olha para a mãe.

Nota-se neste recorte interativo triádico, que a brincadeira teve início com o pegar espontâneo do brinquedo pelo bebê. As ações passam a ser conjuntas com a entrada da mãe na brincadeira, que aproveita o momento em que o bebê manuseia o objeto para estabelecer contato e a atenção dele. $\mathrm{O}$ bebê se envolve na interação quando emite uma resposta não verbal para a mãe, obedecendo a sua solicitação e apertando um botão contido no brinquedo, que emite um som. Esta ação do bebê também demonstra um conhecimento prévio em relação ao objeto, uma vez que a mãe solicita ao bebê demonstrar como o dinossauro faz e ele prontamente aperta o botão no brinquedo. Além destas observações assinala-se que durante este recorte de brincadeira no qual ocorre o manuseio 
do brinquedo, o bebê faz um uso de um gesto intencional ao apertar o botão do brinquedo. $\mathrm{O}$ episódio encerra quando a mãe pega outro brinquedo e dirige a atenção do bebê para este novo objeto.

É possível observar atos intencionais de imitar do bebê neste episódio, uma vez que a mãe solicita ao bebê realizar a ação de imitar o som que o brinquedo emite e o bebê por sua vez obedece à solicitação da mãe e imita o som que o objeto realiza. Além disso, nota-se que a mãe regulou suas ações em função dofeedback que recebeu da criança, o que demonstrou uma participação ativa nas trocas interativas. Estes resultados corroboram o que Tomasello (2003) entende por aprendizagem por imitação, que se dá pela observação das crianças de outras pessoas usando ferramentas e artefatos culturais e promove o comportamento das crianças de tentar se colocar no "espaço intencional" do outro (p.118). Para este mesmo autor, ao imitar, a criança afirma com o outro que entende a funcionalidade do objeto.

Na díade 1, episódio 5 ("o livro"), o recorte interativo triádico teve início com o bebê se dirigindo até a estante do quarto, pegando um livrinho e oferecendo para a mãe. $O$ trecho da interação transcorre como se segue:

A mãe olhando para o bebê pega o livro da mão do bebê e diz: "vamo ver se tem borboleta aqui?!, senta aqui com a mamãe pra gente ver se tem borboleta aqui”. O bebê senta no colo da mãe e vocaliza: "si si”. A mãe segura o livro e diz: "cadê a borboleta?". O bebê olhando para o livro começa a passar rapidamente as páginas. A mãe olhando para a imagem sorri e diz: "o ma caa coo!!!”. O bebê passa rápido todas as páginas e fecha o livro. A mãe observa e diz: "cadê as borboletas que você passou direto?”. O bebê novamente abre e livro, passa todas as páginas e fica observando a última página. A mãe olhando para o livro olha para o bebê e diz: "cadê as borboletas?". O bebê olhando para o livro vocaliza: "ehhh”, depois fecha o livro e vocaliza "abaa".
Constata-se neste episódio que o bebê dá início à brincadeira quando ele pega o livrinho na estante e, olhando para a mãe, oferece o livro para ela, exemplificando um uso intencional do brinquedo. A mãe, por sua vez, utiliza-se deste ato do bebê para estabelecer um momento interativo e buscar a atenção do bebê por meio de solicitações e diretivos, obtendo respostas não verbais (apontar) e verbais do bebê (vocalizações). Autores como Haapsamo et al. (2013) enfatizam que o desenvolvimento da comunicação ocorre em situações interativas e a brincadeira é um aspecto importante dessa interação, pois oportuniza a nomeação dos brinquedos e o subsequente desenvolvimento da linguagem. No recorte acima, a mãe favoreceu a referenciação por meio de gestos como apontar e nomear as imagens, evidenciando o papel da mãe em colaborar para a aquisição da linguagem do bebê em contextos de brincadeira. Além disso, o ato de apontar observado neste recorte, acompanhado pela fala, são partes integrantes da comunicação e tem a função de comunicar e representar a informação (Esteve-Gilbert, \& Prieto, 2013; Novack, $\&$ Goldin-Meadow, 2017).

Autores como Behne et al. (2012) demonstram que bebês de 12 a 18 meses possuem a capacidade de seguir o gesto de apontar de um adulto e, em seguida, inferir os motivos de seu comportamento comunicativo, ou seja, seu objetivo social. Também Aureli et al. (2017) verificaram que aos 12, 15 e 18 meses de idade os bebês podem ser capazes de expressar intenções comunicativas por modalidades vocais e gestuais, e que a frequência do ato de apontar associada aos sons vocais é significativamente maior aos quinze meses.

Diante do exposto, pontua-se que os resultados das análises evidenciam que estes contextos podem ser promotores do desenvolvimento emocional e de capacidades sociocognitivas, pois à medida que a criança se envolve em brincadeiras conjuntas, em um contexto interativo, ocorrem trocas interpessoais, fundamentais para o desenvolvimento de habilidades sociocomunicativas e cognitivas. 
Foi possível observar também deste conjunto de resultados, que os bebês dos três períodos de desenvolvimento analisados fazem uso intencional de brinquedos. Contudo, os bebês de quinze meses exibiram gestos comunicativos intencionais de maneira mais elaborada que os bebês de nove e doze meses, como, por exemplo, quando o bebê apertou o botão do brinquedo para emitir som e quando ele se dirigiu até a estante pegando um livro e entregando à mãe. Comportamentos como estes demonstram que bebês desta idade já possuem habilidades mais sofisticadas tais como o compartilhamento de intenções durante as brincadeiras. Neste sentido, a observação realizada com os bebês e suas mães, em três períodos diferentes, demonstra a relevância da brincadeira e das interações sociais para provocar avanços no desenvolvimento sociocognitivo e linguístico de bebês.

\section{Considerações finais}

O presente estudo buscou analisar as modalidades de brincadeiras e o uso de gestos comunicativos intencionais de bebês aos nove, doze e quinze meses, em situação de brincadeira livre com as mães. Nessa pesquisa evidencia-se o papel da brincadeira como promotora do desenvolvimento de habilidades sociocomunicativas intencionais, sendo esta atividade fundamental para o desenvolvimento global infantil.

Os resultados do estudo indicaram que os tipos de brincadeiras e os gestos comunicativos intencionais variaram principalmente nas interações das mães com os bebês de doze e quinze meses. Esses dois grupos demonstraram comportamentos de maior complexidade em relação aos de nove meses, caracterizados, por exemplo, por gestos como: apontar para objetos fazendo vocalizações, alternar o olhar entre a mãe e o brinquedo (doze meses), verbalizar palavras com uso de apontar e agir de forma espontânea oferecendo objetos à mãe (quinze meses).

Referente ao uso de gestos intencionais durante as brincadeiras e ao manuseio dos brinquedos, os bebês aos nove meses demonstraram explorar os objetos espontaneamente balançando-os ou jogando. Aos doze meses imitaram gestos da mãe realizados com um objeto e usaram espontaneamente objetos para um determinado fim. Aos quinze meses, os bebês fizeram mais usos convencionais dos brinquedos e os manipularam espontaneamente para um determinado fim.

Os resultados encontrados na presente pesquisa apoiam-se em argumentos de Hall, Rumney, Holler e Kidd (2013), Heesen et al. (2017) e Oliveira et al. (2016), que concebem o contexto da brincadeira como uma forma de ação conjunta que supõe um tipo particular de ajustes entre os parceiros de uma interação. Concorda-se com Heesen et al. (2017) quando afirmam que a situação de brincadeira, na qual se estabelece ações conjuntas, constitui um exclusivo contexto para estudar a evolução da intencionalidade compartilhada, própria dos seres humanos. Reafirma-se a importância das interações mediadas por um sujeito mais experiente da cultura durante as situações de brincadeira (Vigotski, 2008), no caso do presente estudo a figura materna, e o potencial desse tipo de contexto para o desenvolvimento de habilidades de comunicação intencional.

Convém destacar a relevância de pesquisas na área da psicologia do desenvolvimento em contextos de ambiente natural, pois possibilita ao pesquisador estar em contato direto com as fontes de suas informações, oferecendo maior descrição do contexto, além de diminuir as tentativas de distorções dos comportamentos das pessoas (Papalia, Olds, \& Feldmam, 2009). Salienta-se que o recurso da videogravação foi um recurso fundamental para permitir rever e analisar de forma minuciosa os episódios interativos.

Ademais, defende-se a continuidade de estudos sobre essa temática por meio da realização de pesquisas empíricas que analisem as interações adulto-bebê desde os primeiros anos de vida, no intuito de subsidiar o planejamento de intervenções precoces junto a psicólogos que atuem em 
contextos de educação e da saúde. Esses estudos podem incluir professores de educação infantil, na perspectiva de levantar informações e fomentar o conhecimento desses profissionais acerca do papel da brincadeira no desenvolvimento de habilidades comunicativas intencionais.

Por fim, os resultados dessa pesquisa reforçam a importância de pais e educadores se engajarem de modo mais efetivo e frequente em atividades de brincadeira com crianças nos primeiros anos de vida para potencializar o desenvolvimento de habilidades sociocomunicativas intencionais, tipicamente humanas, pela relevância dessas habilidades para o desenvolvimento global infantil.

\section{Referências}

Amorim, K. S., Costa, C. A., Rodrigues, L. A., Moura, G. G., \& Rosseti-Ferreira, L. D. P. M. (2012). $O$ bebê e a construção de significações, em relações afetivas e contextos culturais diversos. Temas em Psicologia, 20(2), 309-326. https:// doi.org/10.9788/TP2012.2-03

Aquino, F. de S. B., \& Salomão, N. M. R. (2010). Intencionalidade comunicativa: teorias e implicações para a cognição social infantil. Estudos de Psicologia, 27(3), 413-420. https:// doi.org/10.1590/S0103-166X2010000300013

Aquino, F. de S. B., \& Salomão. N. M. R. (2011). Percepções maternas acerca das habilidades sociocomunicativas de bebês. Revista Psicologia: Ciência e Profissão, 31(2), 252-267. https:// doi.org/10.1590/S1414-98932011000200005

Aureli, T., Spinelli, M., Fasolo, M., Garito, M. C., Perucchini, P., \& D'Odorico, L. (2017). The pointing-vocal coupling progression in the first half of the second year of life. Infancy, 22, 801818. https://doi.org/10.1111/infa.12181

Behne, T., Carpenter M., \& Tomasello M. (2005). One-year-olds comprehend the communicative intentions behind gestures in a hiding game. Development Science, 8(6), 492-499. https:// doi.org/10.1111/j.1467-7687.2005.00440.x
Behne, T., Liszkowski U., Carpenter M., \& Tomasello M. (2012). Twelve-month-olds' comprehension and production of pointing. The British Journal of Developmental Psycology, 30(3), 359-75. https:// doi.org/10.1111/j.2044-835X.2011.02043.x

Carpenter, M., Nagell, K., \& Tomasello, M. (1998). Social cognition, joint attention, and communicative competence from 9 to 15 months of age. Monographs of the society for research in child development, 63(4), 171-175.

Carpenter, M., Tomasello, M., \& Striano, T. (2005). Role reversal imitation and language in typically developing infants and children with autism. Infancy, 8, 253-278. https://doi.org/10.1207/ s15327078in0803_4

Delafield-Butt, J. T., \& Trevarthen, C. (2015). The ontogenesis of narrative: from moving to meaning. Frontiers in Psychology, 6, 1157. https:// doi.org/10.3389/fpsyg.2015.01157

Elkonin, D. B. (2009). Psicologia do jogo. São Paulo: WMF Martins Fontes.

Escandón, V. (2008). Playing with culture. What is the role of musicality and play in the transmission of culture from mother to infant? Infant Observation: International Journal of Infant Observation and Its Applications, 11(3), 257-274. https://doi.org/10.1080/13698030802560133

Esteve-Gilbert, N., \& Prieto, P. (2013). Prosody signals the emergence of intentional communication in the first year of life: Evidence from Catalan-babbling infants. Child Language, 40(5), 919-944. https://doi.org/10.1017/S0305000912000359

Flores, V. L., \& Maggi, N. R. (2012). Reflexões sobre o brinquedo e a brincadeira na formação histórica e cultural humana. Cenários, 1(5) 1-10.

Hall, S., Rumney, L., Holler, J., \& Kidd, E. (2013). Associations among play, gesture and early spoken language acquisition. First Language, 33(3), 294312. https://doi.org/1177/0142723713487618

Hamann, K., Warneken, F., \& Tomasello, M. (2012). Children's developing commitments to joint goals. Child Development, 83(1), 137-145. https://doi. org/ 10.1111/j.1467-8624.2011.01695.x 
Haapsamo, H., Kuusikko-Gauffin, S., Larinen, H. E. K., Kerola, V. P., Soini, H., \& Moilanen, I. (2013). Communication development and characteristics of influencing factors: A follow-up study from 8 to 36 months. Early Child Development and Care, 183(2), 321-334. https://doi.org/10.1080/03004430.2012.674523

Heesen, R., Genty, E., Rossano, F., Zuberbühler, K., \& Bangerter, A. (2017). Social play as joint action: A framework to study the evolution of shared intentionality as an interactional achievement. Learning Behavior, 45(4), 390-405. https://doi.org/10.3758/s13420-017-0287-9

Legrain, L., Destrebecqz, A., \& Gevers, W. (2012). The role of goal-directed behavior in intention attribution in children. Journal of Experimental Child Psychology, 112(3), 351-359.

Legerstee, M. (2013). The developing social brain: Social connections and social bonds, social loss, and jealousy in infancy. In M. Legerstee, D. Haley, \& M. H. Bornstein (Eds.), The infant mind: Origins of the social brain (pp. 223-247). New York, NY: Guilford Press.

Leontiev, A. N. (1988). Os princípios psicológicos da brincadeira pré-escolar. In L. S. Vigotski, A. R. Luria, A. N. Leontiev (Eds.), Linguagem, desenvolvimento e aprendizagem (pp. 119-142). São Paulo: İcone.

Liszkowski, U. (2005). Human twelve-months-olds point cooperatively to share interest with and helpfully provide information for a communicative partner. Gesture, 5(1/2), 135-154. https:// doi.org/10.1075/gest.5.1.11lis

Marques, R. L., \& Bichara, I. D. (2011). Em cada lugar um brincar: reflexão evolucionista sobre universalidade e diversidade. Estudos de Psicologia , 28(3), 381-388.

Melinger, A., \& Levelt, W. J. M. (2004). Gesture and the communicative intention of the speaker. Gesture, 4(2), 119-141. https://doi.org/10.1075/ gest.4.2.02mel

Mendes, D. M.L.F., \& Seidl-de-Moura, M. L. (2004). Desenvolvimento da brincadeira e linguagem em bebês de 20 meses. Revista Psicologia Teoria e Pesquisa, 20(3), 215-222. https://doi. org/10.1590/S0102-37722004000300002

Mendes, D. M. L. F., \& Seidl-de-Moura, M. L. (2009). Expressões faciais de emoção em bebês: importância e evidências. Estudos e Pesquisas em Psicologia. 9(2), 307-327.

Messinger, D. S., \& Fogel, A. (1998). Give and take: The development of conventional infant gestures. Merrill-Palmer Quarterly, 44(4), 566-590.

Nogueira, S. E., \& Seidl de Moura, M. L. (2007). Intersubjetividade: perspectivas teóricas e implicações para o desenvolvimento infantil inicial. Revista Brasileira de Crescimento Desenvolvimento Humano, 17(2), 128-138. https://doi. org/10.7322/jhgd.19839

Novack, M. A., \& Goldin-Meadow, S. (2017). Gesture as representational action: A paper about function. Psychonomic Bulletin Review, 24(3), 652665. https://doi.org/10.3758/s13423-016-1145-z

Nunes, L. L., \& Aquino, F. S. B. (2014). Habilidade de comunicação intencional de bebês: o que pensam as mães? Revista Psicologia: Teoria e Pesquisa, 30(4), 363-372.

Oliveira, K. R. S., Braz-Aquino, F. de S., \& Salomão, N. M. R. (2016). Desenvolvimento da linguagem na primeira infância e estilos linguísticos dos educadores. Avances en Psicología Latinoamericana, 34(3), 457-472. https://doi.org/10.12804/ apl34.3.2016.02

Papalia, D., Olds, S. W., \& Feldman, R. D. (2009). Desenvolvimento humano. Porto Alegre: AMGH/Artmed

Papaeliou, C. F., \& Trevarthen, C. (2006). Prelinguistic pitch patterns expressing 'communication' and 'apprehension'. Journal of Child Language, 33, 163-178. Doi: https://doi.org/ $10.1017 / \mathrm{S} 0305000905007300$

Rivero, M. (2003). Lós inícios de la comunicación: la intencionalidad comunicativa y el significado como procesos graduales. Anuário de Psicologia, 34(3), 337-356.

Rossano, F., Carpenter, M., \& Tomasello, M. (2012). One-year-old infants follow others' voice direc- 
tion. Psychol Sci., 23(11), 1298-1302. https:// doi.org/10.1177/0956797612450032

Smirnova, E. O., \& Riabkova, I. A. (2016). Psychological features of the narrative-based play of preschoolers today. Journal of Russian \& East European Psychology, 53(2), 40-55. https://doi. org/10.1080/10610405.2016.1230993

Sarriá, E. (1991). Observacion de la comunicacion intencional preverbal: um sistema de codificacion basado em el concepto de categoria natural. Psicotema, 3(2), 359-380.

Seidl de Moura, M. L. S., \& Ribas, A. F. P. (2000). Desenvolvimento e contexto sociocultural: a gênese da atividade mediada nas interações iniciais mãe-bebê. Psicologia Reflexão e Crítica, 13(2), 245-256. https://doi.org/10.1590/S010279722000000200005

Striano, T., \& Rochat, P. (1999). Developmental link between dyadic and triadic social competence in infancy. British Journal of Developmental Psychology, 17, 551-562. https://doi. org/10.1348/026151099165474

Striano, T., \& Vaish, A. (2006). Seven-to-9-month-old infants use facial expression to interpret others' actions. British Journal of Developmental Psychology, 24, 753-760.

Schulze, C., \& Tomasello, M. (2015). 18-month-olds comprehend indirect communicative acts. $\mathrm{Cog}$ nition, 136, 91-98. https://doi.org/10.1016/j. cognition.2014.11.036

Tomasello, M. (1995). Joint attention as social cognition. In C. Moore, \& P. J. Dunham (Eds.), Joint attention: Its origins and role in development (pp. 60-83). Hillsdale, NJ: Lawrence Erlbaum Associates.

Tomasello, M. (1999). The human adaptation for culture. Annual Reviews Anthropology, 28, 509-529. https://doi.org/10.1146/annurev.anthro.28.1.509

Tomasello, M. (2003). Origens culturais da aquisição do conhecimento humano. São Paulo: Martins Fontes.

Tomasello, M., \& Rakoczy, H. (2003). What makes human cognition unique? From individual to shared to collective intentionality. Mind and Language, 18(2), 121-147. https://doi. org/10.1111/1468-0017.00217

Tomasello, M., Carpenter, M., Call, J., Behne, T., \& Moll, H. (2005). Understanding and sharing intentions: The origins of cultural cognition. Behavioral and Brain Sciences, 28(5), 1-42. https://doi.org/10.1017/S0140525X05000129

Tomasello, M., \& Carpenter, M. (2007) Shared intentionality. Developmental Science, 10(1), 121-125. https://doi.org/10.1111/j.14677687.2007.00573.x

Viana, K. M. P., \& Pedrosa, M. I. (2014). Brincadeiras coordenadas cooperativas e o compartilhamento de intenções em crianças. Psicologia Reflexão e Crítica, 27(3), 564-572. https://doi. org/10.1590/1678-7153.201427318

Vigotski, L. S. (1986). Lev. S. Vigotki: manuscrito de 1929. Educação \& Sociedade, 17, 21-44.

Vigotski, L. S. (2008). A brincadeira e seu papel no desenvolvimento psíquico da criança. Revista Virtual de Gestão de Iniciativas Sociais, 8, 23-36.

\section{Recebido: setembro 12, de 2018 Aprovado: junho 7, de 2019}

